\title{
PATELLAR TENDON LENGTH AFTER ANTERIOR CRUCIATE LIGAMENT RECONSTRUCTION
}

\author{
D. J. DANDY, S. S. DESAI
}

From Addenbrooke's Hospital, Cambridge, England

We studied changes in patellar tendon length after reconstruction of the anterior cruciate ligament using either the medial third of the patellar tendon as a graft $(n=40)$ or a Leeds-Keio artificial ligament $(n=40)$. Both types of ligament replacement had been supplemented with a MacIntosh extra-articular lateral substitution.

The mean change in length in the tendon graft group was 6\% (SD 5.39); in the Leeds-Keio group it was 2.4\% (SD 4.93). The change in length was significant in both groups, but shortening was more frequent and more severe in the tendon graft group. There was shortening of $10 \%$ or more in $25 \%$ of knees after patellar tendon graft and $7.5 \%$ after use of a Leeds-Keio prosthesis.

J Bone Joint Surg /Br/ 1994; 76-B:198-9.

Received 25 March 1993; Accepted after revision 15 September 1993

Replacement of a ruptured anterior cruciate ligament (ACL) with a free graft of patellar tendon is usually a satisfactory procedure, but some problems have been reported. These include granulomatous lesions on the anterior surface of the graft (Jackson and Schaefer 1990), patellar fracture (McCarroll 1983; Lambert and Cunningham 1988; Christen and Jakob 1992), rupture of the remaining patellar tendon (Bonamo, Krinick and Sporn 1984) or change in its length (O'Brien et al 1991). The last authors reported that the remaining tendon shortened by an average of $20 \%$ in more than half of their patients and that this shortening was associated with anterior knee pain.

We have studied alterations in patellar tendon length after ACL reconstruction, comparing changes after a graft

D. J. Dandy, MD, FRCS, Consultant Orthopaedic Surgeon Addenbrooke's Hospital, Hills Road, Cambridge CB2 2QQ, UK.

S. S. Desai, MCh Orth, MS, DOrth, DNB, Orthopaedic Registrar Broadgreen Hospital, Thomas Drive, Liverpool L14 3LB, UK.

Correspondence should be sent to Mr D. J. Dandy at The Old Vicarage, Great Wilbraham, Cambridge CB1 5JF, UK.

(C1994 British Editorial Society of Bone and Joint Surgery $0301-620 \mathrm{X} / 94 / 2750 \$ 2.00$ had been taken from its medial third with those after the use of a Leeds-Keio prosthetic ligament.

\section{PATIENTS AND METHODS}

We reviewed a series of patients who had had ACL reconstruction for knee instability which had persisted for at least six months and failed to respond to conservative treatment. They all had MacIntosh lateral substitution (Ireland and Trickey 1980) to supplement their intraarticular tendon graft or prosthesis. We excluded patients for whom no adequate lateral radiographs were available, taken in the supine position with the knee flexed to at least $20^{\circ}$ both before operation and at least 12 months later. We then examined the radiographs of the last 40 patients having operations by each of the methods.

Patellar tendon graft. From March 1988 to August 1991, 40 patients had had a patellar tendon graft (Rackemann, Robinson and Dandy 1991). There were 28 men and 12 women; their average age was 27 years (15 to 45 ); there were 21 right and 19 left knees. All knees had been mobilised immediately after operation with no cast fixation. The mean interval between operation and evaluation of the radiographs was 24 months (12 to 48).

Leeds-Keio ligament prosthesis. From November 1983 to January 1988, 40 patients had similar procedures, except that a Leeds-Keio prosthesis (Fujikawa, Iseki and Seedhom 1989) had been used in place of the patellar tendon graft. There were 30 men and 10 women; their average age was 27.5 years (19 to 66); there were 23 right and 17 left knees. The mean interval between operation and evaluation of the radiographs was 48.6 months (24 to 93).

The exposure, the method of attaching the ACL substitute to the tibia, and the postoperative care were identical in both groups. The indications for operation were the same for both groups and all the operations were performed in the same hospital by one surgeon (DJD).

Measurements. On the lateral preoperative and review radiographs, the apparent lengths of the patella and patellar tendon were measured and recorded. Patellar length was assumed to remain constant, so that errors in the measurement of the tendon from variation in projection or magnification could be corrected by a factor derived from the bone measurement. Changes were recorded as percentages of the original length of the tendon. 
Statistical analysis of changes in length was made using Student's paired $t$-test within groups, and Student's unpaired $t$-test between groups. The incidence of changes was compared using the chi-squared test with Yates' correction.

\section{RESULTS}

There was a statistically significant change in the length of the tendon in both the tendon-graft group $(p<0.0004)$ and the Leeds-Keio group $(\mathrm{p}<0.03)$. Shortening was by a mean of $4.26 \%$ ( -7.7 to 22.1 ; SD 6.93$)$ in the tendongraft group and $1.7 \%(-8.1$ to 20.1 ; SD 5.244$)$ in the Leeds-Keio group. This difference was not significant, but the means include results for tendons which lengthened as well as those which became shorter. The mean change in length, either gain or loss, was $6 \%$ (0 to 22.1; SD 5.39) in the tendon-graft group and $2.4 \%$ (0 to 20.1; SD 4.931) in the Leeds-Keio group. This difference was significant $(\mathrm{p}<0.0025)$.

Tendon length at review was unchanged in 10 of the tendon-graft group and 26 of the Leeds-Keio group. Shortening was more frequent in the tendon-graft group $(p<0.002)$, being seen in 23 of the 40 cases; the mean loss of length in this subgroup was $9 \%$ (1.5 to 22.7 ; SD 5.01). In the seven cases in which the remaining tendon had lengthened the mean gain was $5.1 \%$ (3.4 to 7.8; SD 1.468).

In the Leeds-Keio group, 11 of 40 tendons had shortened; the mean loss in this subgroup was $7.5 \%$ (1.9 to $20.8 ;$ SD 6.9). In the three tendons which had lengthened the mean gain was $5 \%$ (2.3 to 8.1 ; SD 2.91).

Shortening by $10 \%$ or more was seen in 10 of the tendon-graft group and 3 of the Leeds-Keio group. Lengthening did not exceed $10 \%$ in any of the 80 patients.

\section{DISCUSSION}

We have confirmed that the patellar tendon may change in length after ACL reconstruction, and have shown that the changes are greater after a free graft has been taken from its medial third than when a prosthetic ligament has been used. There is no clear explanation for these changes, but certain factors may be involved.

We found shortening of over $10 \%$ in 3 of 40 knees (7.5\%) having Leeds-Keio prostheses without excision of a part of the tendon. It seems that dissection or trauma caused by heavy retraction of the medial edge of the tendon may be responsible. By contrast, there was shortening of over $10 \%$ in 10 of the 40 knees (25\%) in which the medial third of the patellar tendon had been taken as a graft; it is possible that relative ischaemia of the remaining ligament caused this excision.

O'Brien et al (1991) found a higher (55\%) incidence of shortening after their use of the central third of the tendon as the graft. They found lengthening of more than $10 \%$ in $20 \%$ of the knees examined. There are, however, differences between our study and that of O'Brien et al apart from the donor site. O'Brien et al sutured the defect in the tendon at operation, immobilised the knee in a cast for six weeks, and used standing radiographs for measurement.

We found changes in length after the insertion of a prosthetic ligament; this suggests that surgical exposure alone can lead to loss of length. Our results, compared with those of O'Brien et al (1991), suggest that use of the medial third of the patellar tendon, leaving the tendon defect unsutured, and early mobilisation may help to reduce the incidence of patellar tendon contracture. It may be important that the tendon is carefully handled during any ACL reconstruction. This could reduce the incidence of shortening and of the anterior knee pain with which it has been shown to be associated.

No benefits in any form have been received or will be received from a commercial party related directly or indirectly to the subject of this article.

\section{REFERENCES}

Bonamo JJ, Krinick RM, Sporn AA. Rupture of the patellar ligament after use of its central third for anterior cruciate reconstruction: a report of two cases. J Bone Joint Surg [Am] 1984; 66-A:1294-7.

Christen B, Jakob RP. Fractures associated with patellar ligament grafts in cruciate ligament surgery. J Bone Joint Surg [Br] 1992; 74-B: 617-9.

Fujikawa K, Iseki F, Seedhom BB. Arthroscopy after anterior cruciate reconstruction with the Leeds-Keio ligament. J Bone Joint Surg [Br] 1989; 71-B:566-70.

Ireland J, Trickey EL. MacIntosh tenodesis for anterolateral instability of the knee. J Bone Joint Surg [Br] 1980; 62-B:340-5.

Jackson DW, Schaefer RK. Cyclops syndrome: loss of extension following intra-articular anterior cruciate ligament reconstruction. Arthroscopy 1990; 6:171-8.

Lambert KL, Cunningham RR. Anatomic substitution of the ruptured ACL using a vascularized patellar tendon graft with interference fit fixation. In: Feagin JA Jr, ed. The crucial ligaments. New York, etc: Churchill Livingstone, 1988:401-8.

McCarroll JR. Fracture of the patella during a golf swing following reconstruction of the anterior cruciate ligament: a case report. Am J Sports Med 1983; 11:26-7.

O'Brien SJ, Warren RF, Pavlov H, Panariello R, Wickiewicz TL. Reconstruction of the chronically insufficient anterior cruciate ligament with the central third of the patellar ligament. J Bone Joint Surg [Am] 1991; 73-A:278-86.

Rackemann S, Robinson A, Dandy DJ. Reconstruction of the anterior cruciate ligament with an intra-articular patellar tendon graft and an extra-articular tenodesis: results after six years. J Bone Joint Surg [Br] 1991; 73-B:368-73. 